\title{
Involvement of pro-inflammatory cytokines and growth factors in the pathogenesis of the Dupuytren's contracture: a novel target for a possible future therapeutic strategy?
}

Enrica Bianchi*1, Samanta Taurone*1, Lia Bardella†, Alberto Signoreキ, Elena Pompili§, Vincenzo Sessall, Caterina Chiappettaף, Lorenzo Fumagalli§̧, Cira Di Gioia**, Francesco S. Pastore††, Susanna Scarpaキキ and Marco Artico*

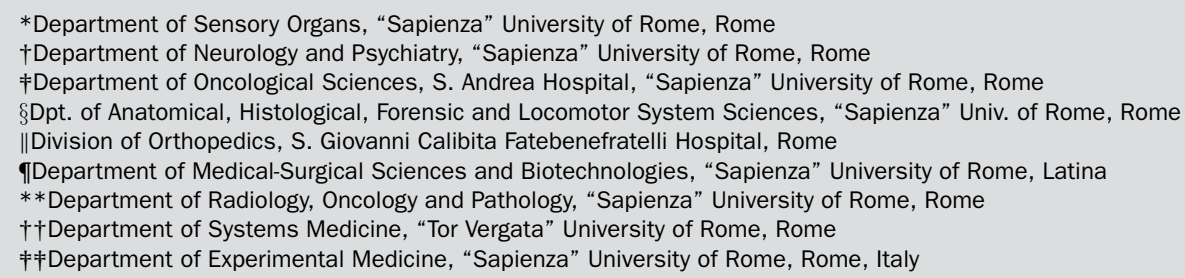

\begin{abstract}
Dupuytren's contracture (DC) is a benign fibro-proliferative disease of the hand causing fibrotic nodules and fascial cords which determine debilitating contracture and deformities of fingers and hands. The present study was designed to characterize pro-inflammatory cytokines and growth factors involved in the pathogenesis, progression and recurrence of this disease, in order to find novel targets for alternative therapies and strategies in controlling DC. The expression of pro-inflammatory cytokines and of growth factors was detected by immunohistochemistry in fibrotic nodules and normal palmar fascia resected respectively from patients affected by DC and Carpal Tunnel Syndrome (CTS; as negative controls). Reverse transcription (RT)-PCR analysis and immunofluorescence were performed to quantify the expression of transforming growth factor (TGF)- $\beta_{1}$, interleukin (IL)- $1 \beta$ and vascular endothelial growth factor (VEGF) by primary cultures of myofibroblasts and fibroblasts isolated from Dupuytren's nodules. Histological analysis showed high cellularity and high proliferation rate in Dupuytren's tissue, together to the presence of myofibroblastic isotypes; immunohistochemical staining for macrophages was completely negative. In addition, a strong expression of TGF- $\beta_{1}$, IL-1 $\beta$ and VEGF was evident in the extracellular matrix and in the cytoplasm of fibroblasts and myofibroblasts in Dupuytren's nodular tissues, as compared with control tissues. These results were confirmed by RT-PCR and by immunofluorescence in pathological and normal primary cell cultures. These preliminary observations suggest that TGF- $\beta_{1}, \mathrm{IL}-1 \beta$ and VEGF may be considered potential therapeutic targets in the treatment of Dupuytren's disease (DD).
\end{abstract}

Key words: cytokines, Dupuytren's contracture, IHC, growth factors, myofibroblasts

\section{INTRODUCTION}

Dupuytren's disease (DD) has been defined as a benign progressive proliferative fibroplasia of the fascia palmaris of the hand, which results in contracture of the fingers and subsequent reduc- tion in the movement and inability to extend them [1]. The pathogenesis of DD still remains unclear; the stages of the fibrotic disease are classified as proliferative, involutional and residual on the basis of the histological appearance of the affected fascia palmaris [2]. The proliferative phase is characterized by

Abbreviations: CTS, Carpal Tunnel Syndrome; DC, Dupuytren's contracture; DD, Dupuytren's disease; DMEM, Dulbecco's essential medium; GAPDH, glyceraldehyde 3 phosphate dehydrogenase; IL, interleukin; PCNA, proliferating cell nuclear antigen; RT, reverse transcription; TGF, transforming growth factor; VEGF, vascular endothelial growth factor

Correspondence: Marco Artico (email marco.artico@uniroma1.it).

1 These authors contributed equally to this work. 
proliferation and differentiation of fibroblasts into myofibroblasts under the influence of several different factors, causing formation of the nodules $[3,4]$. In the second phase, the involutional stage, myofibroblasts proliferate and align along the long axis of surrounding collagens bundles thus giving way to the formation of fibrotic cords [5]. Finally, in the residual phase, the myofibroblasts are replaced by fibrocytes that progressively decrease in number causing the formation of the avascular collagen cord [2]. Myofibroblasts seem to play a central role in the pathogenesis of the fibrotic disease. These cells appear to be an intermediate phenotype between fibroblasts and smooth muscle cells and generate the forces responsible for palmar fascia contracture [6]. Myofibroblasts are responsible for matrix deposition and consequent contraction in DD. Many growth factors and cytokines seem to be implicated in the aetiology of Dupuytren's contracture (DC), among all transforming growth factor $\beta 1$ (TGF- $\beta_{1}$ ) has been suggested to play a predominant role [7]. TGF- $\beta_{1}$ is responsible for the up-regulation of collagens and also of other extracellular matrix components, all fundamental for connective tissue remodelling [8]. TGF- $\beta_{1}$ transduces a signal through an heteromeric complex for formation of related type I and type II transmembrane serine/threonine kinase receptors [9]; the signal of the activated type I receptor induces SMAD signalling cascade and the heteromeric SMAD complexes (SMAD2/3-SMAD4) accumulated in the nucleus regulate the expression of a large array of target genes involved in myofibroblast proliferation, differentiation and extracellular matrix synthesis [10-11]. Several studies have identified pro-inflammatory cytokines in Dupuytren's tissues, but the molecular mechanisms by which inflammatory mediators activate myofibroblast differentiation are still unknown [12]. Interleukin (IL)- 6 was described as being involved in the modulation of TGF- $\beta_{1}$ and its receptor TGF- $\beta$ RII, inducing then fibroblasts proliferation [13]. TNF- $\alpha$ is another central mediator of the fibrotic process, similar to TGF- $\beta_{1}$ [14]: it has been identified as a mediator involved in the differentiation of fibroblasts into myofibroblasts in the palm of patients affected by DD, via activation of Wnt signalling pathway [15]. TNF- $\alpha$ may directly regulate TGF- $\beta_{1}$ expression, as shown in lung fibroblasts [16]. Yet, hypoxia and subsequent angiogenesis seem to play a role in the pathophysiology of this disease [17]. Angiogenesis is induced by several growth factors, but the most important molecule is vascular endothelial growth factor (VEGF), also known as vascular permeability factor [18]. Hypoxia activates the transcription of hypoxia-inducible factor $1 \alpha$ (HIF-1 $\alpha$ ), which itself positively regulates VEGF synthesis [19]. All these findings prompted us to investigate the structural alterations of the fibromatous palmar fascia in patients affected by DC and to analyse expression and localization of the previously described growth factors in surgical samples of palmar aponeurosis. In parallel, immunofluorescence and reverse transcription (RT)-PCR analysis were conducted on primary cultures of fibroblasts and myofibroblasts explanted from Dupuytren's nodules in the proliferative or involutional phases.

\section{MATERIALS AND METHODS}

Tissue samples were obtained from 26 patients ( 22 males and four females, mean age 58 years, mean duration of clinical his- tory 2.5 years) undergoing surgical dermo-fasciectomy for DC $(n=18)$ and Carpal Tunnel Syndrome (CTS, $n=8$, as negative controls). Pathological tissues were sampled from areas of Dupuytren's nodules (four specimens for each nodule). Control samples (two specimens for each tissue fragment), characterized by normal palmar fascia tissues, were collected from patients undergoing hand surgery for CTS.

During excision, apart from anaesthesia, no other chemical products or pharmaceutical drugs have been administered. All samples were collected with the informed consent of the patient and the study protocol conformed to the ethical guidelines of the 1975 Declaration of Helsinki. Experiments were performed in compliance with the Italian laws and guidelines concerning the patients' written informed consent. The Ethics Committee of the Policlinico Umberto I Hospital approved our study according to European Community and Italian laws.

Samples ( 72 from DD and 16 from control patients) were fixed in formalin and embedded in paraffin to be processed for histological staining and immunohistochemistry. The sections were subjected to Haematoxylin and Eosin and Masson's Trichrome staining. In parallel, other tissue samples were used to obtain primary cultures of pathological and normal fibroblasts.

\section{IMMUNOHISTOCHEMISTRY}

The immunohistochemical analysis was conducted using the $\mathrm{ABC} / \mathrm{HRP}$ technique (avidin complexed with biotinylated peroxidase) on $4 \mu \mathrm{m}$ thick paraffin sections that were cut using a rotative microtome. These sections were deparaffinized and hydrated through decreasing ethanol series to distilled water, then subjected to microwave irradiation and immersed in citrate buffer $(\mathrm{pH}=$ 6) twice for $5 \mathrm{~min}$ each time. Subsequently, endogenous peroxidase activity was quenched using $0.3 \%$ hydrogenous peroxide in methanol for $30 \mathrm{~min}$. To evaluate the immunolocalization of pro-inflammatory factors, VEGF, marker of myofibroblasts and proliferating cell nuclear antigen (PCNA), the following antibodies were employed: mouse anti- $\alpha$ SMA monoclonal antibody (Leica; 1:100); rabbit anti-TGF- $\beta_{1}$ polyclonal antibody (Santa Cruz; 1:200); rabbit anti-IL1 $\beta$ polyclonal antibody (Santa Cruz; 1:100); rabbit anti-IL6 polyclonal antibody (Santa Cruz; 1:50); mouse anti-VEGF monoclonal antibody (Santa Cruz; 1:100); mouse anti-TNF- $\alpha$ monoclonal antibody (Santa Cruz; 1:200); mouse anti-ICAM-1 monoclonal antibody (Santa Cruz; 1:25) and mouse anti-PCNA monoclonal antibody (Santa Cruz; 1:100).

Incubation with the primary antibodies was performed overnight at 4oC. Optimal antibody dilution and incubation times were assessed in preliminary experiments. As negative control, the primary antibodies were omitted. After exposure to the primary antibodies, all slides were rinsed twice in phosphate buffer $(\mathrm{pH}=7.4)$ and incubated for $1 \mathrm{~h}$ with the appropriate secondary biotinylated antibody at the final dilution of 1:200. The secondary biotinylated antibodies against rabbit and mouse immunoglobulins were purchased from Abcam (biotinylated goat anti-mouse antibody and biotinylated goat anti-rabbit antibody). 
The slides were then incubated with peroxidase-conjugated avidin (Vector laboratories, Vectastain Elite ABC kit Standard*PK 6-100) for $30 \mathrm{~min}$. Slides were washed in phosphate buffer $(\mathrm{pH}=7.4)$ and treated with $0.05 \% 3$,3-diaminobenzidine (DAB) and $0.1 \% \mathrm{H}_{2} \mathrm{O}_{2}$. Finally, sections were counterstained with Mayer's haematoxylin and dehydrated rapidly. The staining assessment was made by three experts. The intensity of the immune reaction was assessed microdensitometrically using an IAS 2000 image analyser (Delta Sistemi) connected via a TV camera to the microscope. Twelve $100 \mu \mathrm{m}^{2}$ areas were delineated in each section by measuring the diaphragm. The system was calibrated taking the background obtained in sections exposed to non-immune serum as zero. Quantitative data of the intensity of immune staining were analysed statistically by ANOVA followed by Duncan's multiple range test as a post-hoc test. The comparison of the expression levels of each antigen between the palmar fascia from DD and CTS patients was carried out by Student's $t$ test. Statistical analysis was performed using the GraphPad Prism. The results were considered statistically significant with $P<0.05$.

\section{CELLS CULTURE}

Dupuytren's nodule tissues and normal palmar fascia tissues from CTS patients were obtained by surgery. All samples were minced using a sterile technique and placed in sterile $30-\mathrm{mm}$ singlewell culture dishes. The wells were then flooded with $2 \mathrm{ml}$ of Dulbecco's essential medium (DMEM) containing 4\% penicillin/streptomycin (PS, Gibco) and 10\% FBS (Gibco). The media was renewed three times weekly. Cells were observed adhering to the bottom of the wells and were allowed to grow to confluence. The cells were lifted from the wells using Trypsin/EDTA, pelleted, washed and re-suspended in DMEM with $10 \% \mathrm{FBS}$ and $4 \%$ penicillin/streptomycin. Four cell strains were used in these experiments (four from DD patients and four from control patients) and sub-cultured by less than 10 passages.

These primary cultures of pathological and normal cells were used for establishing protein and mRNA expression of specific pro-inflammatory factors and VEGF by immunofluorescence and RT-PCR.

\section{IMMUNOFLUORESCENCE}

For immunofluorescence fibroblast primary cultures were grown directly on Labteck chamber slides (Nunc) for at least $24 \mathrm{~h}$, the cells were then washed with $\mathrm{PBS}$ with $\mathrm{Ca} / \mathrm{Mg}$ and fixed with $4 \%$ buffered paraformaldehyde for $20 \mathrm{~min}$ at $4{ }^{\circ} \mathrm{C}$. Fixed cells were incubated overnight at $4{ }^{\circ} \mathrm{C}$ with the primary antibody for $\alpha$ SMA, TGF $\beta_{1}$, IL $1 \beta$, IL6, TNF- $\alpha$ and VEGF. After three washes in $0.1 \%$ Tween in PBS for $10 \mathrm{~min}$ each, the cells were incubated with the secondary antibody, anti-mouse-fluorescein antibody (Abcam; 1:200) or anti-rabbit- rhodamine antibody (Abcam; 1:200) for $2 \mathrm{~h}$ at room temperature. The nuclei were stained with DAPI (Vectashield Mounting Medium with DAPI, Vector Laboratories). The immunofluorescence was examined by confocal laser microscope (Nikon TE2000). Student's $t$ test was used to evaluate in the expression of each analysed antigen in DD and control cells. The data were considered statistically significant with $P<0.05$.

\section{RT-PCR}

Cultured cells were suspended in TRIzol reagent (Invitrogen Corporation) and total RNA was isolated using RNeasy Micro Kit (Qiagen). Real time PCR was conducted to determine the differences in mRNA expression levels of TGF- $\beta_{1}$, IL$1 \beta$ and VEGF between normal and pathological fibroblasts in culture.

The purity of the RNA was assessed using a UV/visible spectophotomer (SmartSpec 3000, Bio-Rad Laboratories). One microgram of total RNA was reverse transcribed using a high capacity cDNA RT kit (Applied Byosystems) according to the manufacturer's instructions. RNA samples, RT buffer, dNTP mix, $\mathrm{RT}$ random primers, multiscribe reverse transcriptase, RNase inhibitor and DEPC-treated distilled water were added in RNasefree tubes on ice at the final volume of $20 \mu 1$. The thermal cycler was programmed as follows: $25 \mathrm{oC}$ for $10 \mathrm{~min}, 37 \mathrm{oC}$ for $120 \mathrm{~min}$ and the reaction was stopped at $85 \mathrm{oC}$ for $5 \mathrm{~min}$. For the RNA reactions we used the follow primer pairs (Bio Basic In): for TGF- $\beta_{1}$ primer forward 5'-GCTGGACAGGAAGCTGGG$3^{\prime}$ and primer reverse 5'-GGACACAACACGAGCAGAGA-3', for IL-1 $\beta$ primer forward 5'-GCTTCTGGTGATTCCCGCAA3 ' and primer reverse 5'- GGGCTGTGAGAGTTCTTGGG-3', for VEGF primer forward 5'-AACCCCTAGGCCAGGTTGTA3 ' and primer reverse 5'-CGGGATATGGAAGGGAAGCC-3'. For glyceraldehyde 3 phosphate dehydrogenase (GAPDH), we used primer forward 5'-GAGCAGTCCGGTGTCACTAC-3' and primer reverse 5'-TAGTAGCCGGGCCCTACTTT-3'. The specificity of the primers was verified by searching in the NCBI database for any possible homologies to the cDNA of unrelated proteins. Each PCR tube contained the following reagents at the final volume of $50 \mu \mathrm{l}: 0.2 \mu \mathrm{M}$ of forward and reverse primers, $1 \mu \mathrm{g}$ of template cDNA, $0.2 \mathrm{mM}$ dNTP mix, 2.5 units of RedTaq Genomic DNA polymerase (Sigma-Aldrich), $\mathrm{MgCl}_{2}$ and reaction buffer $1 \times$. The amplification was begun with an initial denaturation step at $94^{\circ} \mathrm{C}(2 \mathrm{~min})$ and was followed by 35 cycles, each consisting of denaturation $(30 \mathrm{~s})$ at $94{ }^{\circ} \mathrm{C}$, annealing $(30 \mathrm{~s})$ at the appropriate temperature for each primer pair and extension at $72^{\circ} \mathrm{C}(1 \mathrm{~min})$. Using the comparative critical cycle methods, the expression levels of the target genes were normalized to the GAPDH endogenous control. Data were analysed using the 7900 HT SDS software version 2.1 provided by applied Biosystems.

Statistical analysis was performed using Student's $t$ test (GraphPad Prism). The results were considered statistically significant when the $P<0.05$.

On the basis of these experiments we observed that TGF- $\beta_{1}$ mRNA expression was the most significant among the examined molecules, so we performed real time PCR on paraffinized tissue in order to confirm mRNA expression data obtained from cell 


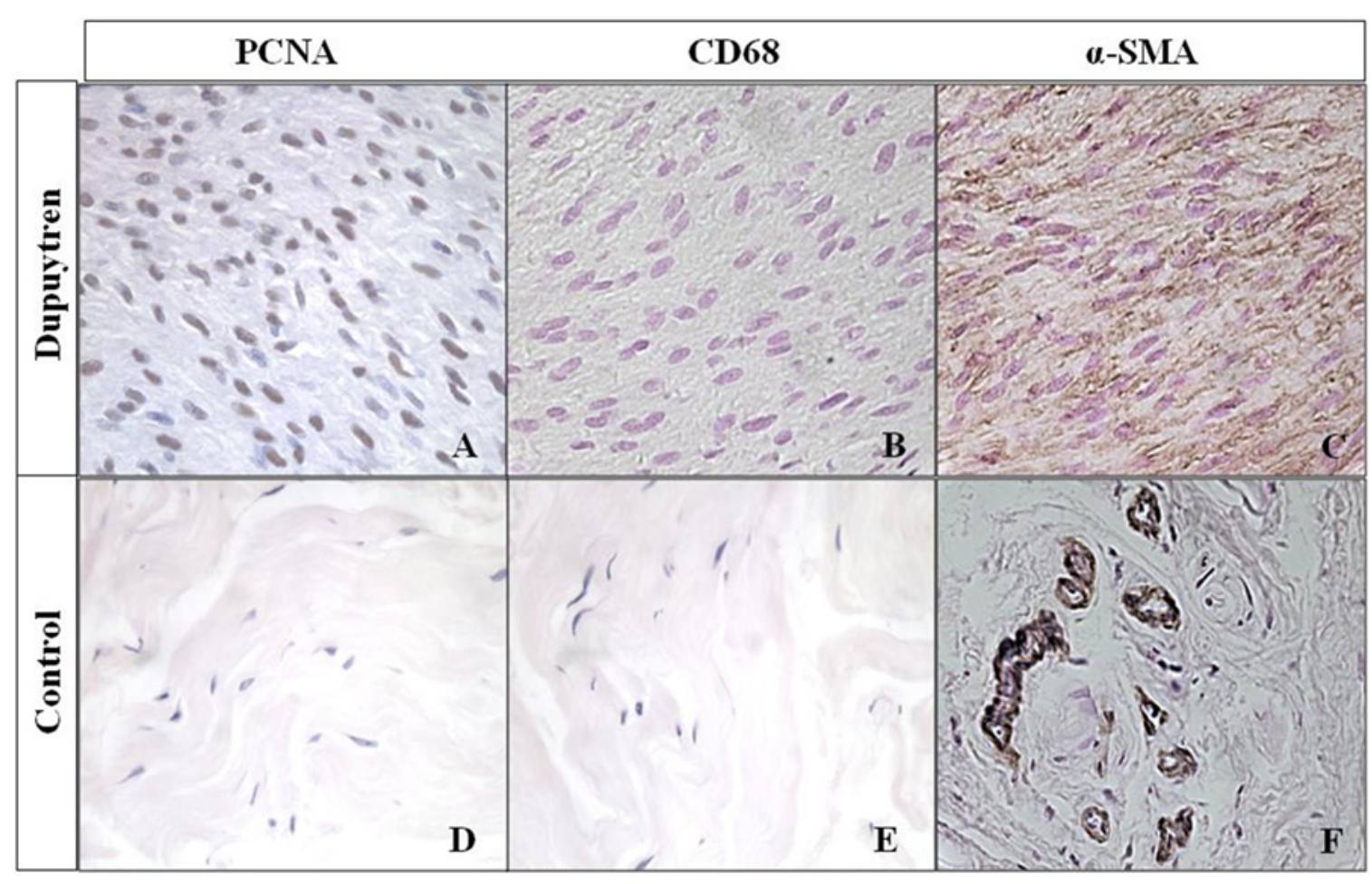

Figure 1 Immunohistochemical analysis of PCNA, CD68 and $\alpha$-SMA markers in Dupuytren's nodules and control tissues The photomicrographs of Dupuytren's nodular tissues showed an increasing number of PCNA (A) and $\alpha$ SMA-positive cells (C) compared with the control tissues in which these markers resulted completely negative (D and $\mathbf{F})$. Immunohistochemistry for CD68 showed that the macrophages and monocytes were completely absent from the pathological nodule (B) similarly to the normal tissue (E). (Magnification 40x).

cultures. For this last procedure, we used the same number of specimens as before (four from DD patients and four from control patients). Real time PCR was performed with the same protocol employed in previously described PCR.

\section{RESULTS}

The rate of cell proliferation was first evaluated in Dupuytren's tissues by analysing the cellular proliferation marker known as PCNA. Fibroblasts and myofibroblasts of Dupuytren's nodules had a strong nuclear staining of PCNA (Figure 1A), in contrast with the normal palmar fascia tissue, in which cell staining was completely absent (Figure 1D). We quantified the number of positive cells on the total number of cells in 10 different areas for each experimental group and we expressed the ratio between PCNA-positive cells and total cells as percentages (Figure 2). The incidence of PCNA-positive nuclei in the fibromatous nodules $(87.65 \% \pm 4.98 \%)$ was significantly $(P<0.0001)$ higher than that in the normal palmar fascia tissues $(18.43 \% \pm 7.15 \%)$. Our data demonstrate that these pathological samples belong to the same proliferative stage of the disease that causes thickening and contracture of the palmar fascia. CD68 immunostaining was performed and it was completely negative in Dupuytren's nodules (Figure 1B) similarly to normal tissues (Figure 1E), thus confirming the absence of macrophages and monocytes in

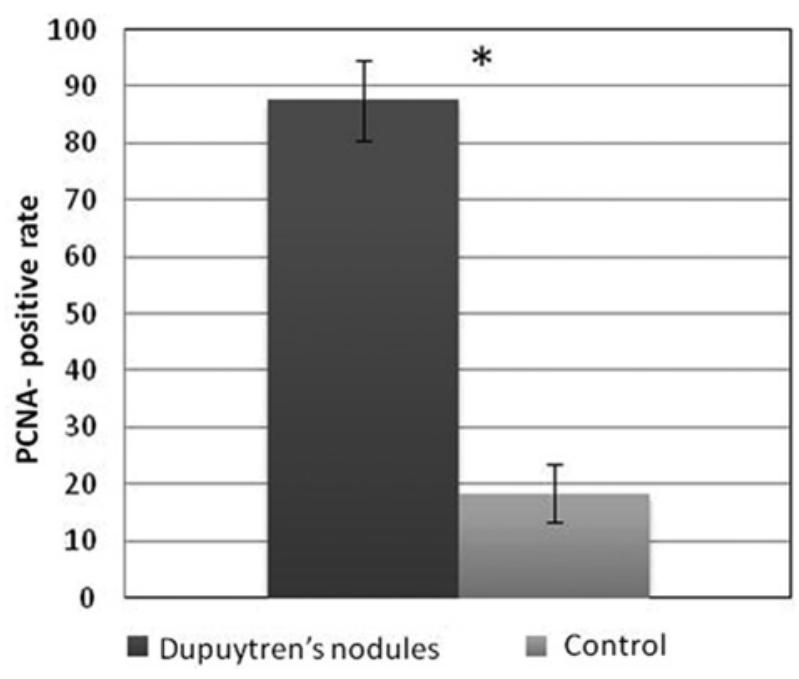

Figure 2 Cell proliferation index in Dupuytren's nodules and normal fascia palmar tissues

PCNA proliferative index is represented as a percentage of PCNApositive nuclei on the total number of cells in Dupuytren's nodules $(87.65 \% \pm 4.98)$ and normal fascia palmar tissues $(18 \% \pm 7.15)$. The bar graph indicates the mean percentage of PCNA positive cells \pm S.D. Statistical analysis is performed using Student's ttest. $* P<0.05$.

the proliferative phase of the disease. Spindle-shaped cells in Dupuytren's nodule resulted $\alpha$-SMA-positive (Figure 1C), this is a reliable marker of the myofibroblastic phenotype; $\alpha$-SMA 


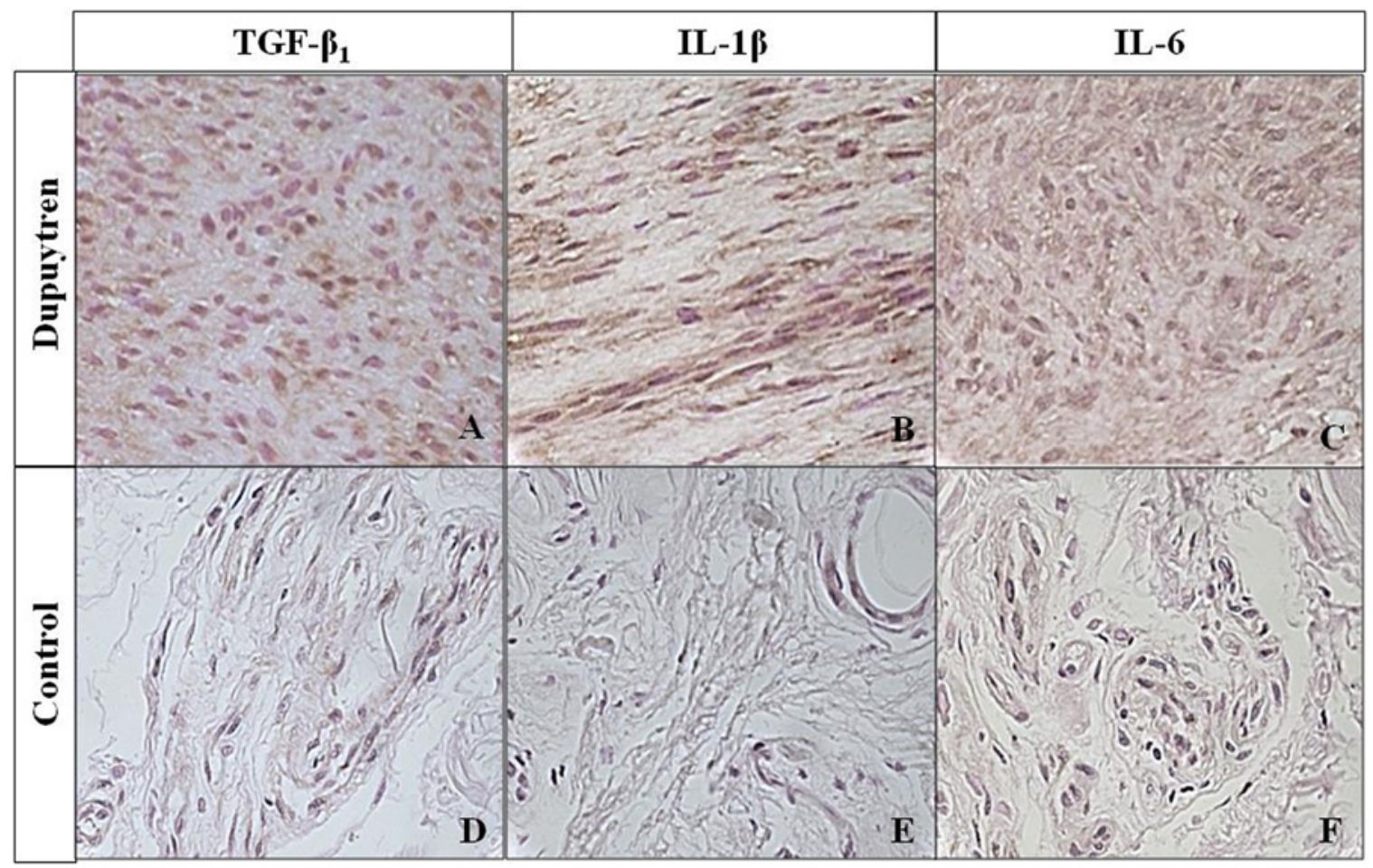

Figure 3 Immunohistochemical analysis of pro-inflammatory markers TGF- $\beta_{1}$, IL-1 $\beta$ and IL-6 in Dupuytren's nodules and controls

TGF- $\beta_{1}$ was strongly expressed in the extracellular matrix and cytoplasm of proliferative myofibroblasts and fibroblasts in the pathological tissue (A). TGF- $\beta_{1}$ was moderately present in the cytoplasm of fibroblasts scattered in the loose connective tissue of normal fascia palmar (D). IL-1 $\beta$ was strongly positive in Dupuytren's myofibroblasts, rich nodules showing cytoplasmic localization (B). IL-1 $\beta$ was completely absent from the extracellular matrix and weakly present in the vascular endothelium and fibroblasts of normal palmar fascia (E). IL-6 was moderately expressed in the extracellular matrix and fibroblasts of Dupuytren's tissues (C) similarly to the control tissue (F). (Magnification $40 \times$ ).

staining was weak or absent from the control tissues (Figure 1F). The $\alpha$-SMA high expression in Dupuytren's tissues confirmed the trans-differentiation from fibroblasts to contractile myofibroblastic phenotype

Then TGF- $\beta_{1}$ was highly expressed in the extracellular matrix and by fibroblasts and myofibroblasts of Dupuytren's proliferative nodules (Figure 3A); at the same time, a weak expression of TGF- $\beta_{1}$ was evidenced in the fibroblasts and vascular endothelial cells of normal tissues, whereas it was completely negative in the extracellular matrix of normal palmar fascia (Figure 3D). IL$1 \beta$ was then evaluated, showing positive immunoreaction in the cytoplasm of fibroblasts and myofibroblasts, extracellular matrix and vascular endothelial cells of the fibro-proliferative nodules (Figure 3B). This pro-inflammatory cytokine was completely absent from the extracellular matrix of control samples, but weakly present in the cytoplasm of capillary endothelial cells and fibroblasts (Figure 3E).

Il-6 was strongly expressed in the extracellular matrix in its soluble form and moderately present in the proliferative myofibroblasts and fibroblasts of the Dupuytren's nodules (Figure 3C). In the controls, IL-6 was completely absent at level of the loose connective tissue but moderately expressed in the vascular endothelial cells and in the fibroblasts (Figure 3F), con- firming that this cytokine is involved in the inflammatory process that activate the fibrotic process of DD.

TNF- $\alpha$ was then analysed and it resulted moderately positive in the extracellular matrix, fibroblasts and vascular endothelial cells of the Dupuytren's proliferative site (Figure 4A) similarly to the control tissue (Figure 4C).

Finally, VEGF was strongly positive in vascular endothelium, fibroblasts and myofibroblasts of Dupuytren's nodules (Figure 4B); differently, VEGF was completely absent from the control tissues (Figure 4D).

All these data were supported by immunofluorescence of the cultured fibroblasts and myofibroblasts isolated from Dupuytren's nodules, in which $\alpha$-SMA was expressed by $50 \%$ of the cells, with uniform cytoplasmic distribution (Figure 5A), confirming the presence of myofibroblasts; whereas $\alpha$-SMA was completely absent from the cells isolated from normal palmar fascia (Figure 5E). Pathological cultured fibroblasts and myofibroblasts were also strongly positive for TGF- $\beta_{1}$ expression, as compared with normal fibroblasts, showing a granular cytoplasmic distribution (Figures 5 B-F). Also, IL-1 $\beta$ was strongly present in Dupuytren's cell cultures (Figure 5C), but weakly present in normal fibroblasts. Finally, IL-6 was weak and moderately present in pathological (Figure 5D) and normal (Figure 5H) cultured cells. 


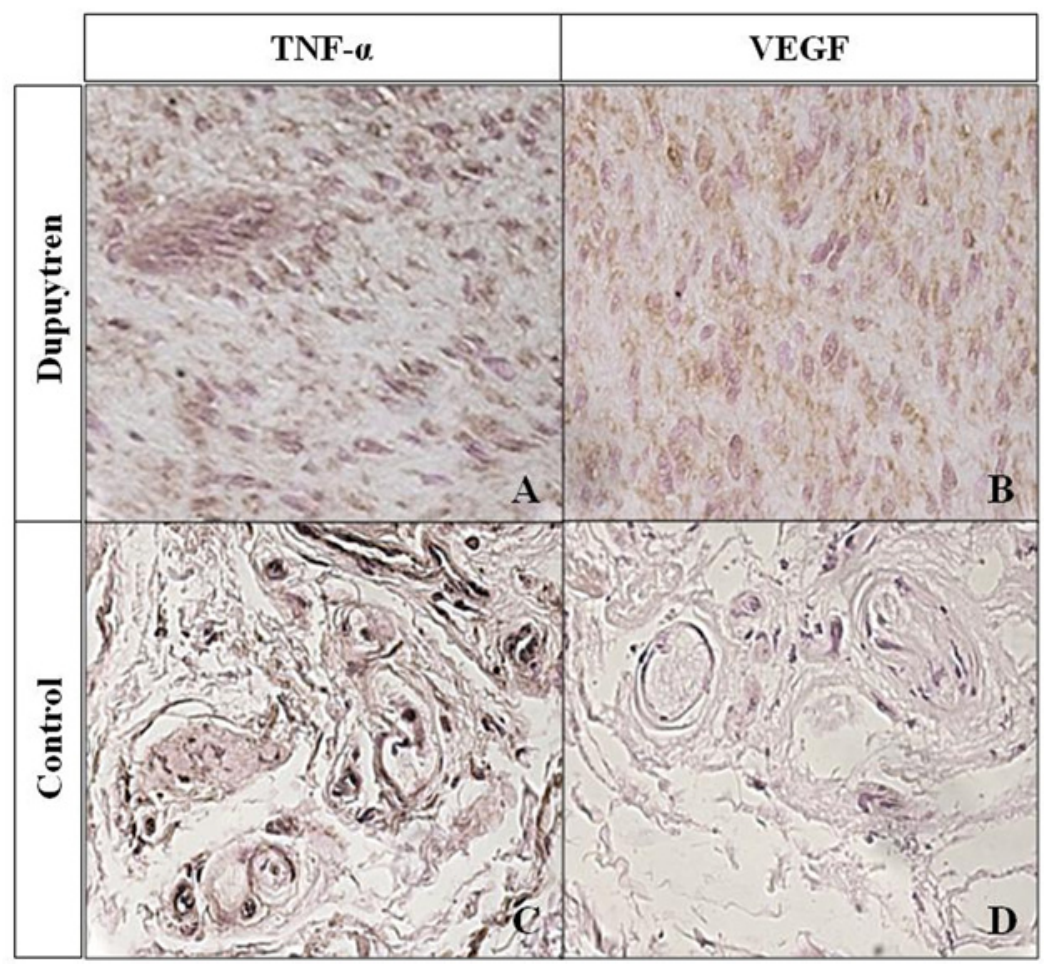

Figure 4 Immunohistochemical analysis of TNF- $\alpha$ and VEGF in Dupuytren's nodules and control tissues

A moderate expression of TNF- $\alpha$ is seen in the extracellular matrix and fibroblasts of Dupuytren's nodules (A) and control tissues (C) (magnification 40x). VEGF immunoreactivity appears to be strongly positive in the extracellular matrix, fibroblasts and myofibroblasts of Dupuytren's nodules (B) (magnification 40x) compared with controls in which the staining was completely absent from the amorphous substance and weakly expressed in the cytoplasm of normal fibroblasts (D) (magnification 20x).

a- SMA
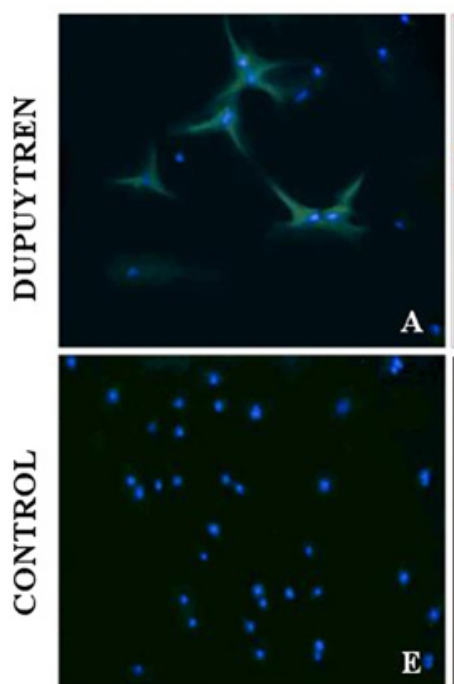

TGF- $\beta 1$
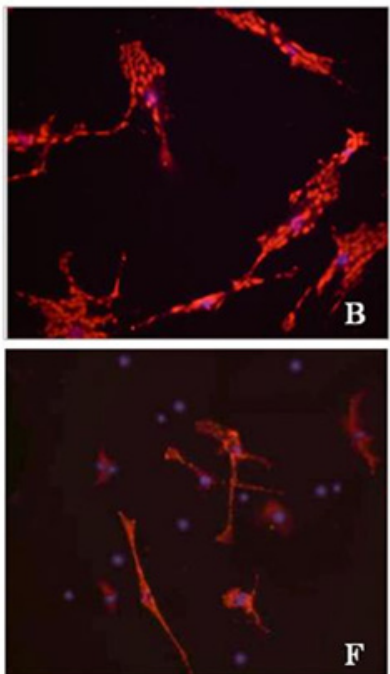

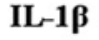
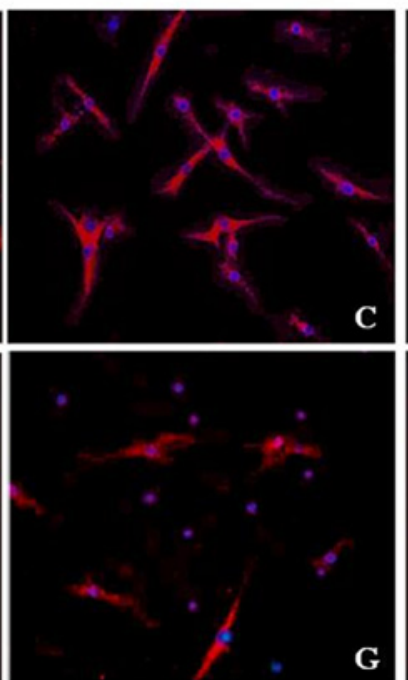

IL-6
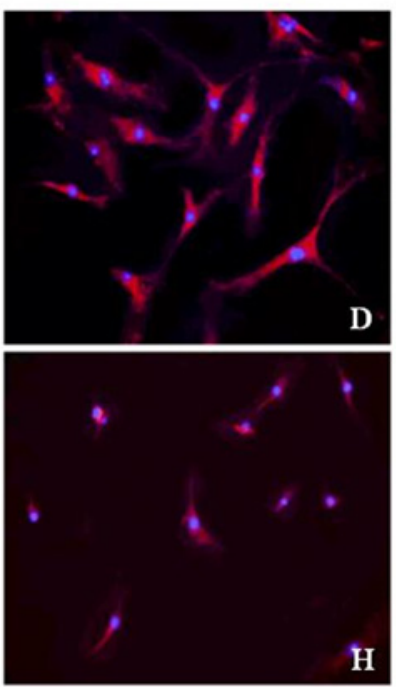

Figure 5 Immunofluorescence for $\alpha$ SMA and pro-inflammatory factors TGF- $\beta_{1}$, IL- $\beta$, IL-6 in fibroblast cultures isolated from Dupuytren's nodules and normal palmar fascia

The pathological fibroblasts isolated from Dupuytren's nodules (A) showed a strong expression of $\alpha$ SMA demonstrating that $50 \%$ of fibroblasts differ in myofibroblasts. In the normal fibroblasts, $\alpha$ SMA expression was completely absent (E). TGF- $\beta_{1}$ and IL- $\beta$ were strongly expressed in the pathological fibroblasts isolated from Dupuytren's tissues (B and C) compared with the normal fibroblasts $(\mathbf{F}$ and $\mathbf{G})$ that showed a weak expression of these pro-inflammatory factors. IL-6 was moderately expressed in the cytoplasm of pathological (D) and normal fibroblasts (H) (magnification $20 \times$ ). 

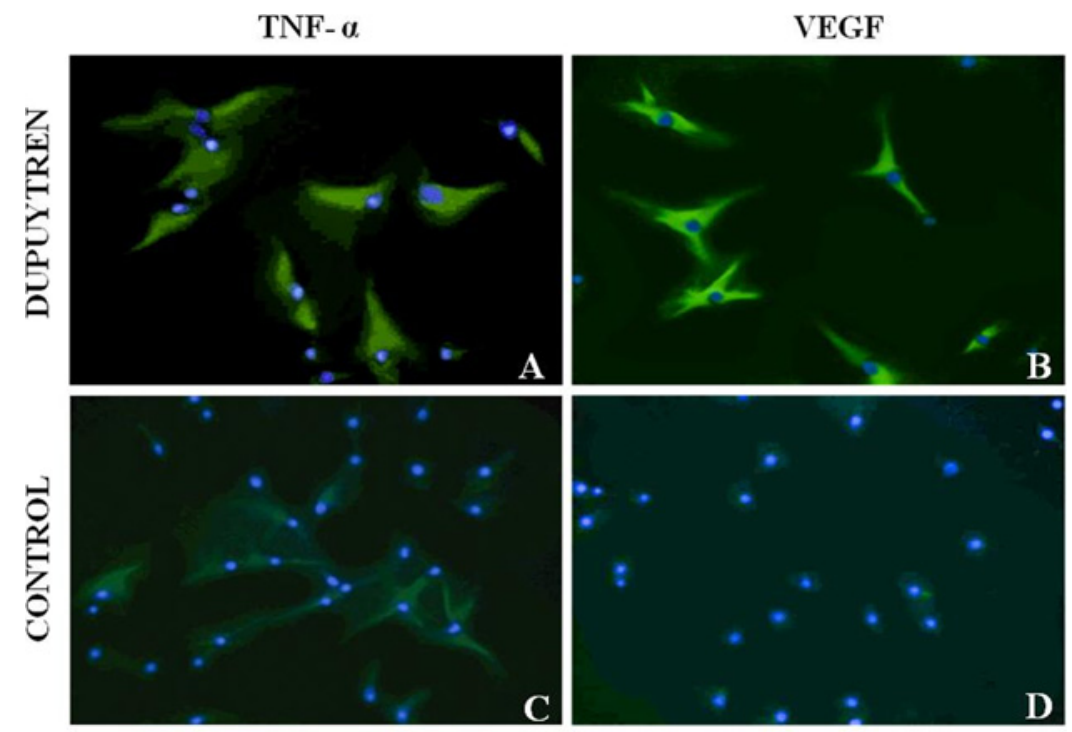

Figure 6 Immunofluorescence for TNF- $\alpha$ and VEGF in fibroblast cells isolated from Dupuytren's nodules and normal palmar fascia

TNF- $\alpha$ was moderately expressed in the pathological fibroblast cultures (A) similarly to the control fibroblasts (C). A strong VEGF expression was found in the cytoplasm of Dupuytren's fibroblasts (B) differently from fibroblasts isolated from normal palmar fascia in which this factor was completely absent (D). (Magnification 20x).

TNF- $\alpha$ was moderately expressed by pathological cells (Figure 6A), similarly to control fibroblasts (Figure 6C). VEGF was found to be strongly expressed in the cytoplasm of fibroblasts and myofibroblasts isolated from Dupuytren's tissue (Figure 6B), whereas was totally absent from normal fibroblasts (Figure 6D).

Our study confirmed that there was no difference in the intensity of the expression of this pro-inflammatory cytokine and in the percentage of TNF- $\alpha$-positive cells between control cells and pathological fibroblasts (Figure 7). The difference in the number of IL-6-positive cells between the pathological and the normal cell lines of fibroblasts was significant for $P<0.05$ (Figure 7).

On the basis of the immunohistochemical and immunofluorescence results that showed a stronger expression of TGF- $\beta_{1}$, IL- $1 \beta$ and VEGF in pathological tissue, respect to normal tissues, we then quantified their differences in mRNA expression between normal and pathological tissues by RT-PCR (Figure 8 ). An up-regulation of TGF- $\beta_{1}(2.30 \pm 0.05)$, IL- $1 \beta(2.02 \pm 0.07)$ and VEGF $(1.97 \pm 0.04)$ was demonstrated in fibroblasts from Dupuytren's nodules compared with normal fibroblasts (Figure 8A). RT-PCR data were demonstrated either on cultured cells or in de-paraffinized tissue samples with $P<0.05$.

\section{DISCUSSION}

DD is a condition in which the formation of nodules in the palm of the hand precedes an eventual contracture of the fingers due to fibrosis [20]. Clusters of macrophages and T-lymphocytes have been observed, in addition to myofibroblasts, in the pathological tissue [6,21-24]. Several growth factors and inflammatory cytokines have been reported in the literature as molecules probably

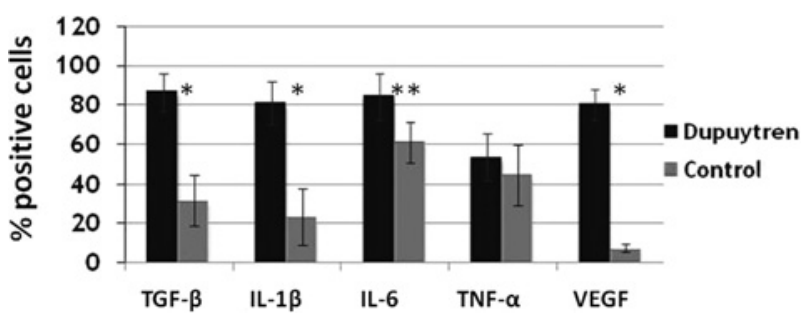

Figure 7 Pro-inflammatory cytokines and VEGF positive cell index in the fibroblasts isolated from Dupuytren's nodules and normal palmar fascia tissue

The bar graph indicates the mean percentage growth factors-posit ive cells + S.D. Statistical analysis is performed using Student's ttest. $* P<0.0001$ or $* * P<0.05$.

involved in the modulation of the pathogenesis of DD [25-27]. TGF- $\beta_{1}$ is undoubtedly one of the cytokines most closely involved in the process of fibrosis and is present at high amounts in sites of chronic inflammation [28-32]. Moreover, some studies have also demonstrated in vitro that cultured Dupuytren's cells produce TGF- $\beta_{1}$ and that TGF- $\beta_{1}$ stimulates the growth of Dupuytren's fibroblasts [33]. As demonstrated by Kulkarni and Karlsson [34], TGF- $\beta_{1}$ plays other important roles in the modulation of fibrosis and inflammation. Our data confirm that TGF- $\beta_{1}$ is more strongly present in DD extracellular matrix and cells, than in the correspondent normal tissue and cells. A new finding, not described in the previous available literature on this topic, is the presence of a cytoplasmic granular fluorescent staining for TGF- $\beta_{1}$, whose characteristic appearance represents an interesting typical finding observed in DD myofibroblasts. 


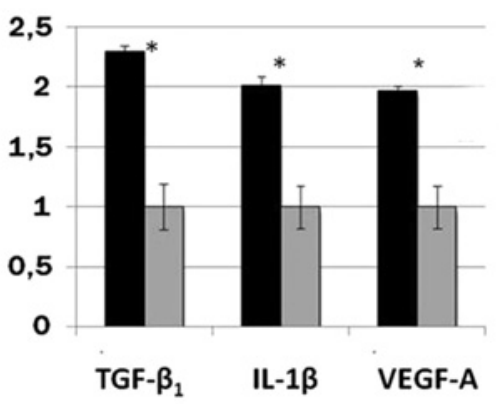

-DUPUYTREN ICONTROL

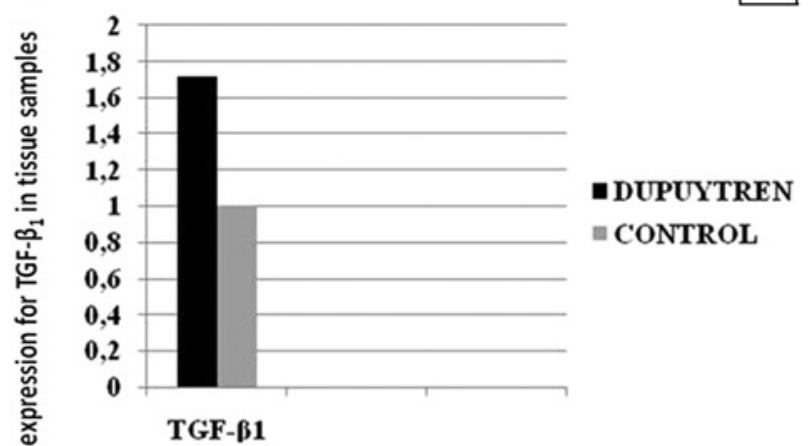

Figure 8 Quantitative PCR analysis in Dupuytren's nodulesderived cells, in control tissue and in paraffinized tissue samples (A, upper) PCR analysis of mRNA expression for TGF- $\beta_{1}, \mathrm{IL}-1 \beta$ and VEGFa in nodules-derived cells and in control normal tissue. Data are presented as mean \pm S.E.M. Statistical analysis is performed using Student's ttest. $* P<0.05$. (B, down) PCR analysis of mRNA expression for TGF- $\beta_{1}$ in paraffinized tissue samples from DD patients and control ones.

A study performed by Iqbal et al. [35] confirmed the importance of myofibroblasts in the pathogenesis of DD and also introduced the possibility of alternative sources of DD myofibroblasts originating from skin overlying nodule (SON) and perinodular fat (PNF). Verjee et al. [15] have recently identified another possible therapeutic target in the TNF, whose role may be hopefully relevant in the better future knowledge of pathogenesis and therapy of DD.

Nowadays, there are different therapeutic options for the treatment of DD [36], but the real question still remains: what is the primary cause in its pathogenesis? An important recent study [37] postulates diverse origins of the myofibroblasts responsible for kidney fibrosis. Notwithstanding the differences in comparison with DD a possible general 'common control' of the mechanisms of fibrosis may be activated even in different areas of the body in response to appropriate stimuli. This 'common control' has to be elucidated in further studies, but it probably constitutes the central problem in DD and in other fibrosis-related pathologies.

Some authors emphasized on the possible role of Wnt signalling [38] in the pathogenesis of DD, but the present study implicates even nine different loci involved in genetic suscept- ibility to DD. The fact that six of these nine loci harbour genes encoding proteins in the Wnt-signalling pathway suggests that aberrations in this pathway may be the key to the process of fibromatosis in DD. However further genome studies should be performed in order to elucidate this interesting hypothesis.

Our results demonstrated that TGF- $\beta_{1}$, IL- $1 \beta$ and VEGF are markedly expressed in Dupuytren's tissue and cultured myofibroblasts. This finding led us to postulate a pivotal role for these molecules in the development of DC. The obtained informations may provide a basis for the research of non-surgical treatment regimens to reduce the recurrence and the progression of this disease, ultimately attenuating hospitalization and post-surgical rehabilitation for patients.

\section{CLINICAL PERSPECTIVES}

- The present study was designed to characterize proinflammatory cytokines and growth factors involved in the pathogenesis, progression and recurrence of $\mathrm{DC}$, in order to find novel targets for alternative therapies and strategies in controlling DC. The pathogenesis of DC still remains unclear. Myofibroblasts are responsible for matrix deposition and consequent contraction in DD. Many growth factors and cytokines seem to be implicated in the aetiology of DC, among all TGF- $\beta$ has been suggested to play a predominant role. TGF- $\beta$ is responsible for the up-regulation of collagens and also of other extracellular matrix components, all fundamental for connective tissue remodelling. Therefore, we have investigated the expression of pro-inflammatory cytokines and of growth factors in fibrotic nodules and normal palmar fascia resected respectively from patients affected by DC and CTS (as negative controls).

- Histological analysis showed high cellularity and high proliferation rate in Dupuytren's tissue, together to the presence of myofibroblastic isotypes. In addition, a strong expression of TGF- $\beta 1$, IL- $1 \beta$ and VEGFa was evident in the extracellular matrix and in the cytoplasm of fibroblasts and myofibroblasts in Dupuytren's nodular tissues, as compared with control tissues. These results were confirmed by RT-PCR and by immunofluorescence in pathological and normal primary cell cultures. Pathological cultured fibroblasts and myofibroblasts were strongly positive for TGF- $\beta 1$ expression, as compared with normal fibroblasts, showing a granular cytoplasmic distribution. Also IL- $1 \beta$ was strongly present in Dupuytren's cell cultures, but weakly present in normal fibroblasts. Finally, IL6 was weak and moderately present in pathological and normal cultured cells.

- Our results demonstrated that TGF- $\beta$, IL- $1 \beta$ and VEGFa are markedly expressed in Dupuytren's tissue and cultured myofibroblasts. This finding led us to postulate a pivotal role for these molecules in the development of DC. The obtained informations may provide a basis for the research of non-surgical treatment regimens to reduce the recurrence and the progression of this disease, ultimately attenuating hospitalization and post-surgical rehabilitation for patients. Therefore TGF- $\beta 1$, 
IL-1 $\beta$ and VEGFa may be considered as potential therapeutic targets in the treatment of DD.

\section{AUTHOR CONTRIBUTION}

???.

\section{ACKNOWLEDGMENTS}

The authors are grateful to Mrs. Sharon Hobby for her kind and careful revision of the English language of the manuscript.

\section{FUNDING}

This work was supported by the Enrico ed Enrica Sovena Foundation [grant number XXXXXXXX].

\section{REFERENCES}

1 Calandruccio, J.H. (1998) Dupuytren contracture. In Campbell's Operative Orthopaedic, 9th edn. (Terry, C.S., ed.), pp. 4274-4276, Mosby, St. Louis

2 Luck, J.V. (1959) Dupuytren's contracture: a new concept of the pathogenesis correlated with surgical management. J. Bone Joint Surg. Am. 41, 635-664 PubMed

3 Desai, S.S. and Hentz, V.R. (2011) The treatment of Dupuytren disease. J. Hand. Surg. Am. 36, 936-942 CrossRef PubMed

4 Shih, B. and Bayat, A. (2010) Scientific understanding and clinical management of Dupuytren disease. Nat. Rev. Rheumatol. 6, 715-726 CrossRef PubMed

5 Schurch, W., Skali, I. and Gabbiania, G. (1990) Cellular biology. Dupuytren's Disease (McFarlane, R.M., McGrouther, D.A. and Flint, M.H., eds), pp. 31-34, Churchill Livingstone, New York

6 Gabbiani, G. and Majno, G. (1972) Dupuytren's contracture: fibroblast contraction? An ultrastructural study. Am. J. Pathol. 66, 131-138 PubMed

7 Kloen, P. (1999) New insights in the development of Dupuytren's contracture: a review. Br. J. Plast. Surg. 52, 629-635 CrossRef PubMed

8 Badalamenti, M.A., Sampson, S.P., Hurst, L.C., Dowd, A. and Miyasaka, K. (1996) The role of TGF-beta in Dupuytren's disease. J. Hand. Surg. 21A, 210-215 CrossRef

9 Heldin, C.H., Miyazono, K. and Ten Dijke, P. (1997) TGF-beta signaling from cell membrane to nucleus through SMAD proteins. Nature 390, 465-471 CrossRef PubMed

10 Schmierer, B. and Hill, C.S. (2007) TGF $\beta$-SMAD signal transduction: molecular specificity and functional flexibility. Nat. Rev. Mol. Cell Biol. 8, 970-982 CrossRef PubMed

11 Tomasek, J.J., Gabbiani, G., Hinz, B., Chaponnier, C. and Brown, R.A. (2002) Myofibroblasts and mechano-regulation of connective tissue remodeling. Nat. Rev. Mol. Cell Biol. 3 , 349-363 CrossRef PubMed

12 Andrew, J.G., Andrew, S.M., Ash, A. and Turner, B. (1991) An investigation into the role of inflammatory cells in Dupuytren's disease. J. Hand. Surg. 16, 267-271 CrossRef

13 Ito, H. (2003) IL-6 and Crohn's disease. Curr. Drug Targets Inflamm. Allergy 2, 125-130 CrossRef PubMed

14 Sanchez-Muñoz, F., Dominguez-lopez, A. and Yamamoto-Furusho, J.K. (2008) Role of cytokines in inflammatory bowel disease. World J. Gastroenterol. 14, 4280-4288 CrossRef PubMed

15 Verjee, L.S., Verhoekx, J.S.N., Chan, J.K.K., Krausgruber, T. Nicolaidou, V., Izadi, D., Davison, D., Feldmann, M., Midwood, K.S. and Nanchahal, J. (2013) Unraveling the signaling pathway promoting fibrosis in Dupuytren's disease revels TNF as a therapeutic target. PNAS 110, 928-937 CrossRef
16 Sullivan, D.E., Ferris, M., Pociask, D. and Brody, A.R. (2005) Tumor necrosis factor-alpha induces transforming growth factor-beta 1expression in lung fibroblasts through the extracellular signal-regulated kinase pathway. Am. J. Respir. Cell Mol. Biol. 32, 342-349 CrossRef PubMed

17 Holzer, L.A., Cor, A., Pfandlsteiner, G. and Holzer, G. (2013) Expression of VEGF, its receptors, and HIF-1a in Dupuytren disease. Acta Orthopaedica 84, 420-425 CrossRef PubMed

18 Tischer, E., Michell, R., Hartman, T., Silva, M., Gospodarowicz, D., Fiddes, J.C. and Abraham, J.A. (1991) The human gene for vascular endothelial growth factor. Multiple protein forms are encoded through alternative exon splicing. J. Biol. Chem. 266 , 11947-11954 PubMed

19 Ke, Q. and Costa, M. (2006) Hypoxia-inducible factor-1 (HIF-1). Mol. Pharmacol. 70, 1469-1480 CrossRef PubMed

20 Meek, R.M., McLellan, S. and Crossan, J.F. (1999) Dupuytren's disease: a model for the mechanism of fibrosis and its modulation by steroids. Bone Joint Surg. 81, 732-738 CrossRef

21 Iwasaki, H., Muller, H., Stutte, H.J. and Brennscheidt, U. (1984) Palmar fibromatosis (Dupuytren's contracture): ultrastructural and enzyme histochemical studies of 43 cases. Virch. Arch. A. 405, 41-53 CrossRef

22 Scurch, W., Seemayer, T.A. and Gabbiani, G. (1992) Myofibroblast. In Histology for pathologists (Sternberg, S.S., ed.), pp. 118-125, Raven Press, New York

23 Azzarone, B., Failly-Crepin, C., Daya-Grosjean, L., Chaponnier, C. and Gabbiani, G (1983) Abnormal behaviour of cultured fibroblasts from nodule and non-affected aponeurosis of Dupuytren's disease. J. Cell Physiol. 117, 353-61 CrossRef PubMed

24 Baird, K.S., Alwan, W.H., Crossan, J.F. and Wojciak, B. (1993) T-cell mediated response in Dupuytren's disease. Lancet 341, 1622-1623 CrossRef PubMed

25 Baird, K.S., Crossan, J.F. and Ralston, S.H. (1993) Abnormal growth factor and cytokine expression in Dupuytren's contracture. J. Clin. Pathol. 46, 425-428 CrossRef PubMed

26 Meek, R.M.D, Wojciak, B. and Crossan, J.F. (1996) Dupuytren's fibroblasts secrete interleukin-8, a powerful lymphocyte chemoattractant. British Society for Surgery of the Hand Birmingham

27 Baird, K.S. (1994) Aetiopathogenesis of Dupuytren's contracture. Rheumatol. Rev. 3, 111-123

28 Roberts, A.B., Sporn, M.B., Assoain, R.K., Smith, J.M., Roche, N.S., Wakefield, L.M., Heine, U.I., Liotta, L.A., Falanga, V. and Kehrl, J.H. (1986) Transforming growth factor type beta: rapid induction of fibrosis and angiogenesis in vivo and stimulation of collagen formation in vitro. Proc. Natl. Acad. Sci. U.S.A. 83, 4167-4171 CrossRef PubMed

29 Raghow, R., Postlethwaite, A.E., Keski-Oja, J., Moses, H.L. and Kang, A.H. (1987) Transforming growth factor-beta increases steady state levels of type I procollagen and fibronectin messenger RNAs posttranscriptionally incultured human dermal fibroblasts. J. Clin. Invest. 79, 1285-1288 CrossRef PubMed

30 Massague, J., Heino, J. and Laiho, M. (1991) Mechanisms in TGF-beta action. Ciba. Found. Sym. 157, 51-59

31 Ignotz, R.A. and Massague, J. (1986) Transforming growth factor beta stimulates the expression of fibronectin and collagen and their incorporation into the extracellular matrix. J. Biol. Chem. 261, 4337-4345 PubMed

32 Wahl, S.M., Costa, G.L., Mizel, D.E., Allen, J.B., Skaleric, U. and Mangan, D.F. (1993) Role of transforming growth factor beta in the pathophysiology of chronic inflammation. J. Peridontol. 64, 450-455

33 Kloen, P., Jennings, C.L., Gebhardt, M.C., Springfield, D.S. and Mankin, H.J. (1995) Transforming growth factor-beta: possible roles in Dupuytren's contracture. J. Hand. Surg. Am. 20, 101-108 CrossRef PubMed 
34 Kulkarni, A.B. and Karlsson, S. (1993) Transforming growth factor-beta knockout mice: a mutation in one cytokine gene causes a dramatic inflammatory disease. Am. J. Pathol. 143, 3-9 PubMed

35 lqbal, S.A., Manning, C., Syed, F., Kolluru, V., Hayton, M., Watson, S. and Bayat, A. (2012) Identification of mesenchymal stem cells in perinodular fat and skin in Dupuytren's disease: a potential source of myofibroblasts with implications for pathogenesis and therapy. Stem Cells Dev. 21, 609-622 CrossRef PubMed

36 Eaton, C. (2014) Evidence-based medicine: Dupuytren contracture. Plast. Reconstr. Surg. 133, 1241-1251 CrossRef PubMed
37 Falke, L.L., Gholizadeh, S., Goldschmeding, R., Kok, R.J. and Nguyen, T.Q. (2015) Diverse origins of the

myofibroblasts: implications for kidney fibrosis. Nat.

Rev. Nephrol. 11, 233-244

CrossRef PubMed

38 Dolmans, G.H., Werker, PM., Hennies, H.C., Furniss, D., Festen, E.A., Franke, L., Becker, K., Van Der Vlies, P., Wolffenbuttel, B.H., Tinschert, S. et al. (2011) Dutch Dupuytren Study Group,

German Dupuytren Study Group, the LifeLines Cohort Study, and the BSSH-GODD Consortium. Wnt signaling and Dupuytren disease. N. Engl. J. Med. 365, 307-317

$\underline{\text { CrossRef }} \underline{\text { PubMed }}$

Received 26 May 2015/29 January 2015; accepted 11 June 2015

Published as Immediate Publication 11 June 2015, doi: 10.1042/CS20150088 